\title{
ENSINANDO POR CÓDIGOS: construindo uma docência padronizada
}

\author{
Rita de Cássia Prazeres Frangella \\ Universidade do Estado do Rio de Janeiro - UERJ, Brasil
}

\begin{abstract}
Resumo
Este estudo discute a padronização do ensino, incitada pelo advento da Base Nacional Comum Curricular e como seu desenho curricular se constitui dispositivo de regulação do trabalho docente. Com problematização inspirada na obra de Peter Taubaman (2009), focaliza os usos e significação dos códigos alfanuméricos que identificam e organizam as competências e habilidades descritas na BNCC. Argumenta-se que formulação dos códigos e a forma como são apresentados constituem dispositivos de regulação do trabalho docente, participando da construção discursiva que adensa uma lógica de responsabilização docente pela qualidade e sucesso da educação. O recurso ao uso de códigos se alinha também ao fortalecimento de uma cultura de auditoria nos processos educacionais. Lendo os códigos na/da BNCC pelas lentes derridianas, discute-se como a BNCC impõe uma normatividade originária e polarizada que limita e condiciona as possibilidades de produção curricular em outros contextos e, nessa linha, implica a anulação de qualquer decisão e esforços para contenção da diferença e supressão das contingencialidades. Defende-se o investimento na análise dessa intrincada articulação discursiva que envolve as significações acerca da educação, ensino e trabalho decente, bem como os afetos que participam desse processo.
\end{abstract}

Palavras-chave: Políticas curriculares; Discurso; Normatividade; Cultura de auditoria; Afeto.

\begin{abstract}
This study discusses the standardization of teaching, incited by the arrival of the Common National Curriculum Base and how its curricular design constitutes a guideline for regulating teaching work. The problematization was inspired by the work of Peter Taubaman (2009), it focuses on the uses and meaning of alphanumeric codes that identify and organize the competencies and abilities described in the BNCC. It is argued that the formulation of such codes and the way in which they are presented constitute guidelines for regulating the work of teaching. They participate in the discursive construction that reinforces a logic of teacher accountability for the quality and success of education. The use of codes is also in line with the strengthening of an auditing culture in educational processes. Reading the codes in/of the BNCC through Derridian lenses, it is discussed how the BNCC imposes an original normativity that restraint and conditions the possibilities of curriculum production in other contexts. In this line, it implies the annulment of any decision and efforts to contain the difference and suppression of contingencies. It is defended the investment in the analysis of this intricate discursive articulation that involves the meanings related to education, teaching and teachers' work, as well as the affections that are involved in this process.
\end{abstract}

Keywords: Curriculum policies; Discourse; Normativity; Audit culture; Affection.

ISSN 1645-1384 (online) www.curriculosemfronteiras.org 
O que estamos testemunhando hoje é algo novo e muito mais perigoso do que o culto à ciência ou o "culto da eficiência". Sua singularidade reside em sua difusão, sua ameaça aos próprios fundamentos da educação pública, sua ampla aceitação pelo estabelecimento educacional, seu ataque direto à vida intelectual, estética e ética dos professores e sua radical incompreensão do ensino ${ }^{1}$ (Taubman, 2009, p. 5 - tradução livre)

Essa reflexão se faz a partir da leitura do livro de Peter Taubman (2009), "Teaching by numbers - desconstruction the discourse of standards and accountability in Education". Nessa obra, o autor investe numa análise da retórica em torno da standartização do ensino, sua articulação num discurso que passa a fazer com que o estabelecimento de um padrão seja compreendido como medida de equidade e justiça curricular e como essa padronização erige e sustenta um discurso de responsabilização docente.

Em diálogo com o autor e a partir do título da sua obra, nomeio e anuncio o mote de problematização que trago nesse texto: a conformação da atividade docente ao cumprimento de standards estabelecidos na BNCC (Brasil,2018), apresentados na descrição de competências e habilidades e que se expressam enquanto tal no uso dos códigos alfanuméricos que acompanham essas competências.

Argumento que essa formulação dos códigos e a forma como são apresentados constituem dispositivos de regulação da prática docente e reverberam numa construção discursiva que se apropria dessa linguagem em rearticulações que adensam uma lógica de responsabilização docente pela qualidade e sucesso da educação, resignificando tanto qualidade quanto sucesso, parametrizados por uma perspectiva de que esses são mensuráveis. Tal perspectiva incide tanto na prática docente na educação básica como também na formação de professores, tal como temos acompanhado com as recentes proposições que focalizam a formação de professores, tanto inicial quanto continuada, e que tomam a Base por base, preservando e proliferando tal perspectiva.

Desenvolver essa reflexão se dá partir de relatos e imagens dessa apropriação que nos provocam. Recentemente, um post nas redes sociais me chamou atenção: professoras "presenteadas" com cards com os objetivos apresentados na BNCC, diferenciando com cores as diferentes áreas do conhecimento, e com indicação dos respectivos códigos alfanuméricos. Seria fácil para as professoras seguirem a BNCC! Busco então, discutir a proposição feita aos professores: que balizem seu trabalho pelos códigos, observando os processos de significação para a docência que se espraiam dessa perspectiva, indagando como esses discursos operam.

Essa interrogação é formulada em diálogo com as perspectivas discursivas que tem orientado as pesquisas que desenvolvi/desenvolvo, que tomam política e cultura como produções discursiva, processos de significação contínuos e ininterruptos que se dão na indeterminação, contingência e iterabilidade. Derrida $(2004,2011)$ e Bhabha $(2001,2013)$ figuram como principais interlocutores nessa composição teórica de feições pós-estruturais e pós-coloniais. Dessa perspectiva se erige o que venho postulando: currículo como 
produção político-discursiva, como enunciação cultural. E é a partir desse pressuposto que tomo como objetivo dessa reflexão o que Butler (2018) enuncia:

[...] Na minha opinião, o coração de qualquer projeto político radical é justamente esse movimento de interrogação do artifício da autoridade que busca evitar a contestação (p.71).

É esse o foco desse texto: problematizar os códigos como signos de uma autoridade normativa que, dada a sua assertividade, é tomada como verdade incontestável, expressão racional de uma proposição clara, objetiva e comum, o que por si só já inferiria sobre seu compromisso com a igualdade, sendo então per si uma proposição democrática, numa rasa cadeia linear que vai justapondo essas significações como caminho racional e factível de acessar uma educação democrática. Abalar o que é dado como fato é o desafio posto.

\section{Códigos Alfanuméricos - o que são e como se apresentam na BNCC}

A primeira menção aos códigos alfanuméricos na BNCC se dá na seção 2, "Estrutura da Base", em que se anuncia que se explicará a composição dos códigos alfanuméricos criados para identificar as aprendizagens.

Eles assim são apresentados, primeiramente em relação a Educação Infantil e, a seguir, no âmbito do Ensino Fundamental: 


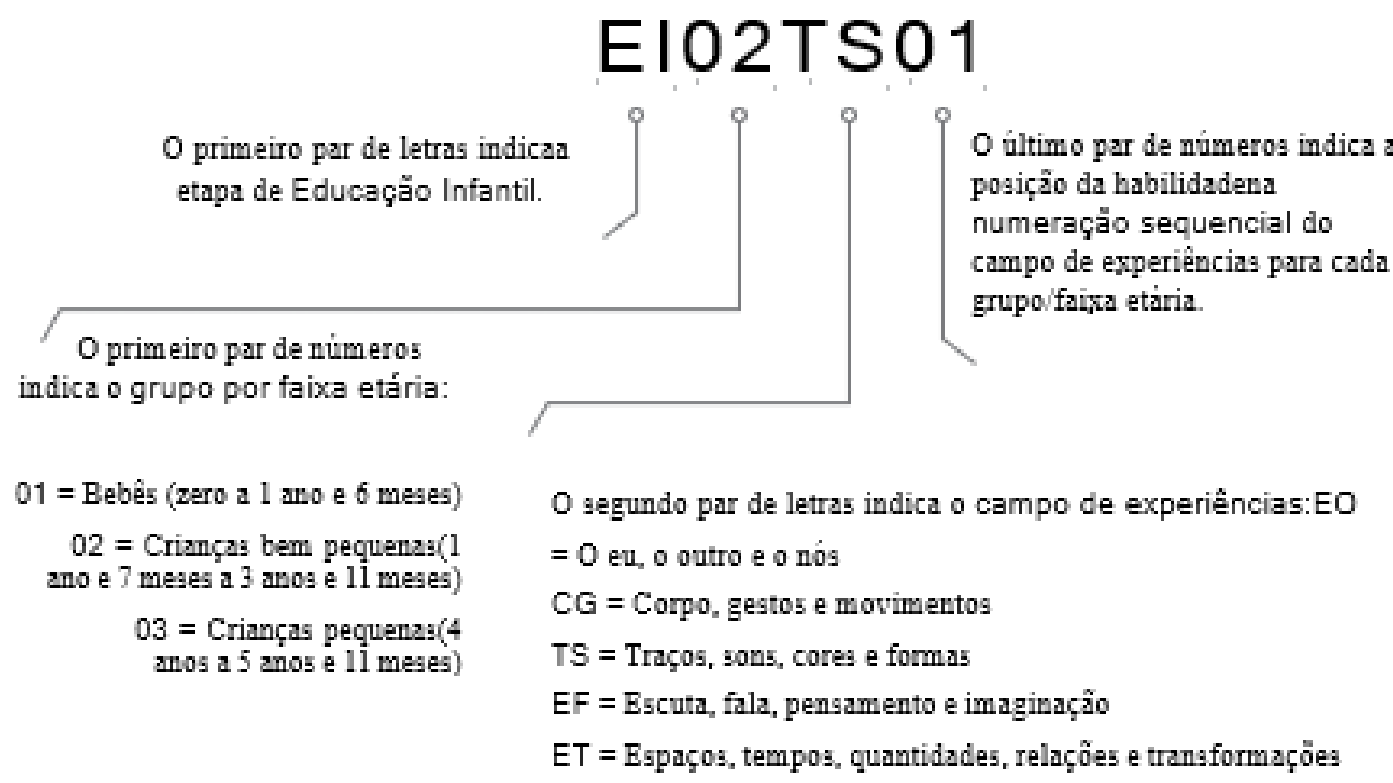

Segundo esse critério, o código EI02TS01 refere-se ao primeiro objetivo de aprendizagem e desenvolvimento proposto no campo de experiências "Traços, sons, cores e formas" para as crianças bem pequenas (de 1 ano e 7 meses a 3 anos e 11 meses).

Cumpre destacar que a numeração sequencial dos códigos alfanuméricos não sugere ordem ou hierarquia entre os objetivos de aprendizagem e desenvolvimento. (Brasil, 2018, p.26) 


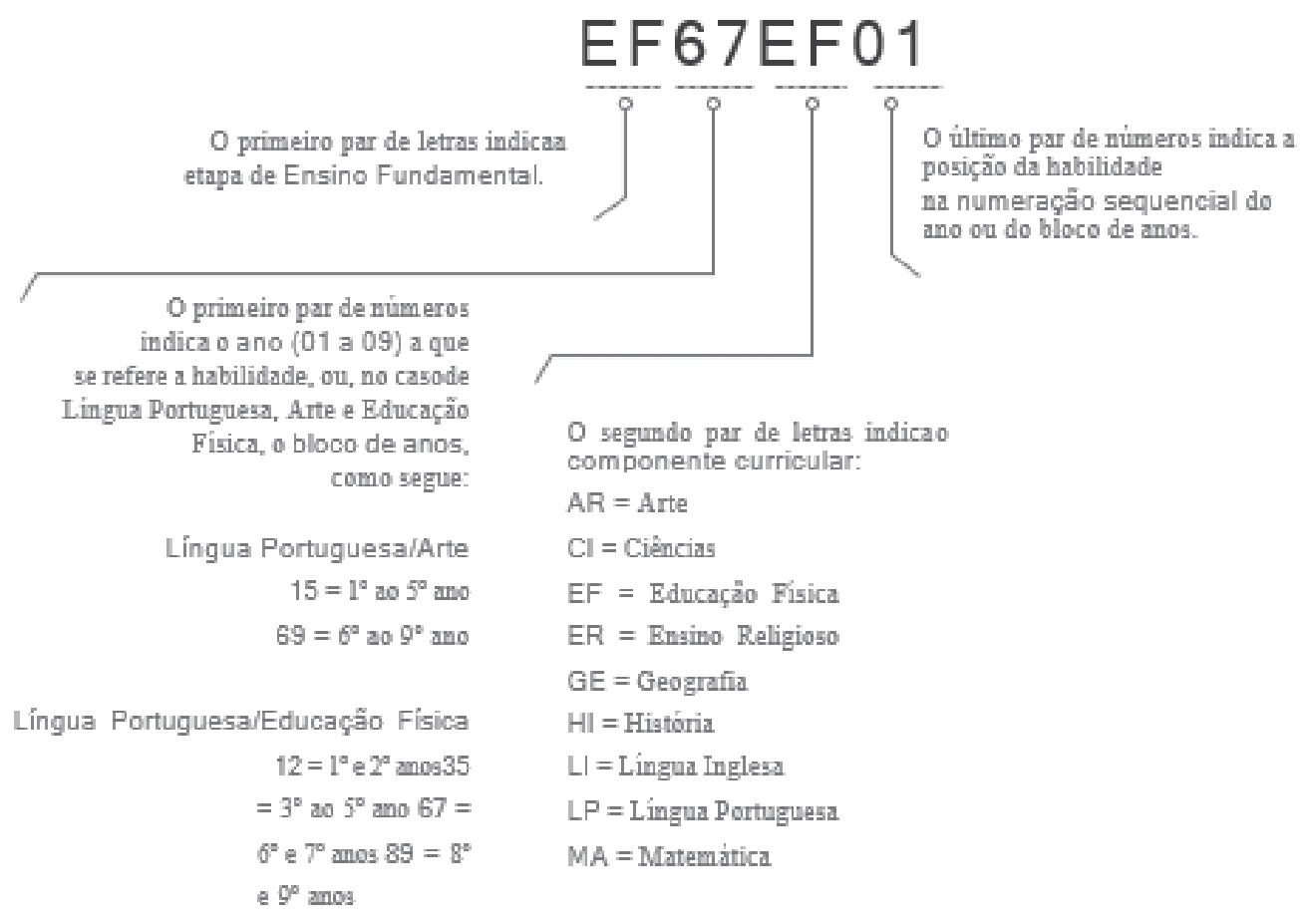

(Brasil, 2018, p.30)

Não há uma discussão maior sobre o recurso ao uso desses códigos, apenas a advertência de que esses não implicam em ordem e hierarquia; assim sua presença é naturalizada. Parece ser uma escolha simples, apenas com fins organizativos e de forma a facilitar o "manuseio" da BNCC. Contudo, suas funções vão ficando mais claras na medida que os códigos figuram como item que requer atenção específica no processo de implementação da BNCC.

No site oficial http://basenacionalcomum.mec.gov.br/, na parte dedicada a implementação, há um direcionamento a materiais de apoio do ProBNCC - Programa de Apoio à Implementação da BNCC, instituído por decreto em abril de 2018 e que organiza, com a gestão do MEC, o processo de implementação da BCNN em Estados e municípios a partir da perspectiva de pacto federativo, disponibilizando recursos para montagem de equipes redatoras dos currículo e orientando o planejamento dessa etapa, nos moldes da construção da BNCC - com consulta pública, equipe de redatores, etc.

Nessa seção há uma parte dedicada aos materiais de apoio a serem utilizados pelas equipes responsáveis pela adaptação curricular/reelaboração - termo usado pelo ProBNCC - 
à luz da BNCC. Esses materiais são agrupados por temáticas - Currículo, Consulta Pública, Tutoriais e Orientações.

Na temática Currículo se encontra o material "Sugestões para códigos nos currículos estaduais de Referência". Nesse momento os códigos ganham cena e seu papel nas significações que se depreendem da BNCC ficam mais visíveis:

Este material tem o objetivo de apoiar as equipes de currículo dos estados* na organização das habilidades e objetivos de aprendizagem e desenvolvimento.

Apresentamos aqui uma sugestão sobre códigos para habilidades e objetivos de aprendizagem e desenvolvimento que podem ser adotados nos estados e podem ser adaptados de acordo com seu contexto e planejamento. A organização de códigos nos currículos dos estados é importante porque:

- Os livros do PNLD e outros materiais didáticos oferecidos em nível nacional estarão organizados utilizando os códigos da BNCC.

- É interessante que os códigos utilizados nos currículos dialoguem com os códigos da BNCC, para facilitar que o professor acesse materiais relevantes às habilidades do currículo local que são disponibilizados em nível nacional.

- O professor terá como principal referência o seu currículo local, construído a partir da BNCC.

- O diálogo entre redatores de currículo e a relação entre os documentos curriculares de diferentes localidades fica facilitado.

- Outras plataformas e sistemas podem usufruir de um padrão para representar as habilidades e objetivos de aprendizagem e desenvolvimento. (MEC, s/d, p.2. Disponível

em:

http://basenacionalcomum.mec.gov.br/images/implementacao/3. Orienta coes_para_codigos_dos_curriculos_locais_v7.pdf. Acesso em jul/2021)

Parece, à primeira vista, que o recurso ao uso dos códigos se justifica, mais uma vez, em termos de facilitação, o que é reforçado a cada item. Essa apresentação expõe sem dúvida um caráter prático e instrumental, mas diferente do que é dito em termos de facilitar o acesso a outros materiais e plataformas, facilita também uma rede de controle que adensa processos de centralização curricular.

Observa-se aí uma questão que marca a produção da BNCC e que produz sentidos para a educação: o fortalecimento de um discurso técnico, instrumental, que se baseia em protocolos prescritivos passíveis de controle; uma noção da educação coisificada, que Biesta (2020) chama de processo de educação nos termos de uma transação econômica. O autor chama atenção para como essa perspectiva é facilitada pela nova linguagem da aprendizagem. Mais uma vez a facilidade aparece em cena.

O que não é fácil é observar como essa learnificação, termo usado por Biesta (2012) para se referir a primazia da linguagem da aprendizagem, produz efeitos e significação para a educação e para o trabalho docente. $\mathrm{O}$ autor, ao trazer a ideia da learnificação como crítica às perspectivas prevalentes nas políticas educacionais, adverte que não se opõe a 
aprendizagem, que é parte da questão educacional, mas o que é percebido na emergência da linguagem da aprendizagem é a redução da educação aos termos de resultados, o que restringe e oblitera sentidos de educação, subsumidos no entendimento de que resultados são expressão de qualidade. Tal perspectiva se espraia para a atuação docente na injunção objetivo-qualidade. Os descritores funcionam como prescrições que buscam ordenar e definir o trabalho docente, como dispositivo de uma normatividade neoliberal que ganha terreno. $\mathrm{O}$ que se depreende disso é que, em resposta a lógica de accountability vigente, o caminho é ensinar por códigos.

Taubamn (2009) também dedica particular atenção as ciências da aprendizagem e sua relação com a educação. A proeminência que o foco na aprendizagem adquire, lida como sucesso em testes padronizados, a faz então ser perseguida como meta, a operacionalização da aprendizagem se constitui foco do trabalho, enfatizando o desempenho indicado nos objetivos comportamentais, que retomam o discurso da racionalidade tyleriana que alicerça a elaboração curricular na definição de objetivos/metas e requer formas de verificar o êxito do proposto. Para tanto, devem ser criadas experiências de aprendizagem que permitam tal logro. (Lopes e Macedo, 2011).

A produção dos standards e seus códigos correlatos permite que se desenvolvam estratégias de monitoramento curricular, que se dá via observação de desempenhos e resultados de testes, no alinhamento linear entre resultado e qualidade. A proposição de organização dos currículos locais a partir do modelo da BNCC, replicando os códigos como forma de apresentação/organização de habilidades legitima a BNCC e a centralidade da avaliação estandardizada como medida de qualidade; capilariza e institui estratégias de controle das "contingências", como um antídoto preventivo às contingencialidades dos contextos locais que poderiam "deturpar" a BNCC, na linha do que Miller (2014) astutamente chamou de "excessiva obsessão de produtores de testes e gurus de avaliações por "certeza", que compreende currículo somente como "conhecimento predeterminado, empacotado, fixo, imutável e possível de ser testado” (p. 2051). Busca por certezas que se insinuam nas práticas normalizadas e normalizantes que objetivos/habilidades codificados estabelecem.

Assim, os objetivos de desenvolvimento/habilidades se convertem em metas a serem alcançadas e regulam o trabalho docente, no incremento de uma noção de responsabilização individual pela qualidade da educação regida por uma lógica gerencial.

Trato nos termos de responsabilização individual pois, tal como apresentado, os códigos ao facilitarem o acesso dos professores a diferentes plataformas, materiais didáticos e de permitir que se orientem no trabalho com os documentos curriculares vigentes tornam o processo simples e organizado de tal forma que intercorrências são evitáveis e quando não, se trata de questão de não utilização adequada dos recursos disponíveis. Num percurso comum a todos, desvios não são imaginados, uma vez que os arranjos são feitos de forma a garantir clareza e precisão, otimizando o processo em curso e, quando tal intento não é alcançado, trata-se então de erro ou falha de execução, passível também de ser localizado na identificação daquele que falhou.

Há uma intenção de homogeneização e universalização a partir do que é estabelecido na BNCC e isso se evidencia na atenção dada aos usos dos códigos no âmbito das orientações 
dadas no ProBNCC. Observa-se a indicação de manutenção dos códigos, usados de forma que possa ser pareado o currículo local à BNCC, "facilitando" também a identificação e controle sobre a implementação, num nexo causal que estabelece a BNCC como origem da política e para qual convergem todas as ações, mantendo a lógica que orientou a proposição/homologação da Base Nacional Comum Curricular, trata-se de uma homogeneização dos processos pedagógicos numa perspectiva de universalidade normativa que interdita possibilidades de diferimento. (Frangella, 2020).

A tomada da BNCC impõe uma normatividade originária que limita e condiciona as possibilidades de produção curricular em outros contexto. Tomar a BNCC como ponto originário implica o entendimento dessa como a verdade a ser replicada e conservada, centro/fundamento das elaborações curriculares posteriores que a refletem como espelho. Reprime-se a diferença, o jogo das significações como Derrida (2011) discute, e com ele me alinho quando afirma que "o espaço do jogo foi sempre o lugar e a chance de transformação do dogmatismo político" (Derrida, 2004, p.294)

A problemática da origem foi foco de investimento de Derrida ao pensar a impossibilidade do alcance da origem, da verdade transcendental, do fundamento último. Estabelecer a BNCC como origem fixada é entendê-la como centro que estrutura as relações e, determinada como presença do que se é, impede a transformação, o jogo de ser jogado

Abalar a centralidade da estrutura remete a um descentramento que perturba a origem absoluta de sentido, e então não mais presença, mas um não-lugar atravessado por substituições indefinidas, tudo se torna discurso (Derrida, 2011, p. 408). É na impossibilidade da origem que se inscreve a diferença. Lendo os códigos na/da BNCC pelas lentes derridianas podíamos com o autor pensar:

O conceito de estrutura centrada é com efeito o conceito de um jogo fundado, constituído a partir de uma imobilidade fundadora e de uma certeza tranquilizadora, ela própria subtraída do jogo. A partir dessa certeza, a angústia pode ser dominada, a qual nasce sempre de uma certa maneira de estar implicado no jogo, de ser apanhado no jogo, de ser como ser logo de início do jogo. (Derrida, 2011, p.408)

Assim, o jogo marcado pelos códigos é estabelecido, apresentando as jogadas possíveis: 


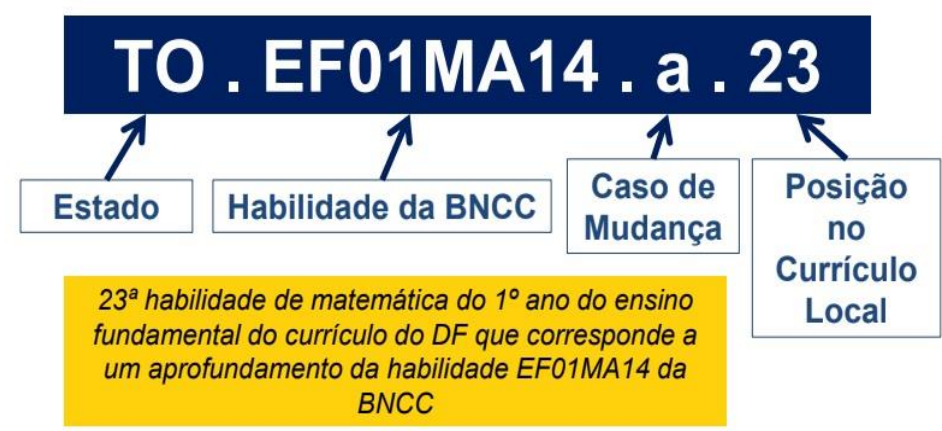

Fonte: MEC, s/d, p.3 Disponível em:

http://basenacionalcomum.mec.gov.br/images/implementacao/3._Orientacoes_para_codigos_dos_c urriculos locais v7.pdf. Acesso em jul/2021.

Destaca-se nessa proposição a possibilidade de identificação precisa de qual objetivo/habilidade da BNCC é "apropriado" e qual a "posição no currículo do Estado" essa habilidade ocupa. O que primeiramente chama atenção é a relação estabelecida com a alteridade do Outro na busca de uma mesmidade, numa significação do comum como igualdade que, para tanto, implica na neutralização das diferenças em nome de uma universalidade (Bhabha, 2013).

A ideia de uma normatividade originária se faz mais forte na observação do que é indicado como sendo terceira parte na composição do código - a letra que indica o caso de mudança. Esses casos são assim estabelecidos: 


\section{POSSÍVEIS CASOS \\ SEM MODIFICAÇÃO \\ CONTEXTUALIZAÇÃO \\ APROFUNDAMENTO \\ DESDOBRAMENTO \\ NOVA HABILIDADE \\ OU OBJETIVO}

Fonte: MEC, s/d, p.5 Disponível em:

http://basenacionalcomum.mec.gov.br/images/implementacao/3. Orientacoes para codigos dos c urriculos_locais_v7.pdf. Acesso em jul/2021

E sua conceituação é descrita como:

Sem modificação - A habilidade ou objetivo reflete exatamente a mesma aprendizagem da BNCC;

Contextualização - A habilidade no currículo contém um elemento local que não está presente na habilidade original da $\mathrm{BNCC}$;

Aprofundamento - A habilidade no currículo contém orientações pedagógicas que não estão na habilidade original da BNCC;

Desdobramento - A habilidade original da BNCC foi desdobrada em mais de uma no currículo;

Nova Habilidade ou objetivo - A habilidade no currículo trata de uma aprendizagem não contemplada na BNCC.

Múltiplos Casos - Por exemplo, contextualiza, aprofunda e desdobra - usar apenas um dos modificadores.

(MEC, s/d, p.6-12 Disponível em: http://basenacionalcomum.mec.gov.br/images/implementacao/3. Orienta coes_para_codigos_dos_curriculos_locais_v7.pdf. Acesso em jul/202)

Tal como posto, a ideia propalada de que BNCC e currículos tem papéis complementares, que decisões curriculares é que vão adequar a BNCC aos contextos locais, nos termos do documento de que "considerando a autonomia dos sistemas ou das redes de ensino e das instituições escolares, como também o contexto e as características dos alunos (Brasil, 2018, p.16)", o que cabe então às escolas e as redes, contudo, é observado aqui não de outra forma que não a subordinação. Há um expediente que, sob a forma de organização zelosa e atenta, institui uma "decisão" - para manter o termo utilizado na BNCC e nas orientações para implementação - curricular tutelada, condicionada a réplica, um saber de 
normas que se apoia em uma autoridade prévia que delega ao outro a decisão, o que com Derrida (2004) penso como simultaneamente sendo a anulação de qualquer decisão.

Não há decisão, uma vez que essa demanda incondicionalidade. Não há decisão se não a que se dá na singularidade do contexto. Não há decisão onde cada jogada se dá previamente esquadrinhada, então as peças se movem no tabuleiro seguindo um roteiro preciso e prescrito previamente. Não há jogo, nem decisão, nem responsabilidade.

Uma decisão, que valha ser significada como tal, demanda uma dimensão de alteridade que prescinde de uma normatividade que enquadra e fixa na busca de estratégias de contenção da imprevisibilidade; uma decisão para ser decisão se dá sem garantias que assegurem isso ou aquilo, não se encolhe em assertivas absolutas e normalizantes que podem destitui-la de seu traço alteritário. Ecoando Derrida (2004), "em primeira ou última instância, o que há a ser feito é inventado ou inaugurado e, portanto, advém sem programa. (p.118)"

Contudo é preciso esclarecer, como faz o autor, que não se trata de ode ao relativismo, nem lógica causuísta, mas se trata de indecidibilidade, que rompe com uma estrutura binária da metafísica opositiva, não para inaugurar um terceiro lugar, entre um e outro. É uma suspensão da polaridade, descentramento que não possibilita a oposição ser/não ser, verdade/não verdade, e daí não determina, nem condiciona a decisão, que sem garantia, se dá como acontecimento e alteridade.

E a partir dessa perspectiva que aciono a leitura dos códigos como dispositivo de regulação do trabalho docente, que condicionam qualidade e sucesso às demonstrações cada vez mais objetivas de forma tornar o processo pedagógico auditável, uma lógica gerencial que expurga o que não pode ser objetificado, verificado, rastreado. Assim, os aspectos gerenciais se espraiam e se exacerbam; controle e regulação são expressões dessa lógica.

Os códigos alfanuméricos cumprem o papel de instrumento simultâneo de controle e regulação permitindo a auditoria dos processos pedagógicos e daí a identificação da responsabilização pela má gestão do processo. Nessa lógica, de uma cultura de auditoria, é necessário o desenho dos processos e a criação de ferramentas de controle para o acompanhamento da aderência a estes, no caso, os códigos funcionam como indicadores dessa aderência ao mesmo tempo que também funcionam como métrica do processo.

Nessa linha, os códigos como indicadores/métricas se fazem presente nas articulações possíveis de serem percebidas nos materiais didáticos e nas avaliações sistémicas. No edital Programa Nacional do Livro Didático - PNLD 2022 (Edital de Convocação - CGPLI 02/2020), que trata da convocação para participação no processo de seleção de obras didáticas, literárias e pedagógicas para o ano de 2022 voltado para a educação infantil e alfabetização, no anexo III, que versa sobre os critérios gerais da avaliação pedagógica das obras, é indicado:

As obras observarão os critérios de coerência e adequação da abordagem teóricometodológica, devendo:

2.4.1. Organizar-se de forma estruturada, garantindo a progressão das aprendizagens e fornecendo um itinerário claro, sequencial e determinado para o professor conduzir suas aulas. 


\subsubsection{Referenciar-se na Base Nacional Comum Curricular - BNCC} (Brasil/FNDE, 2020, p.32)

Cruzando tais disposições com a produção de obras didáticas, num exercício de análise dos efeitos desse arranjo, tomo como exemplo materiais didáticos disponíveis na íntegra para a consulta dos professores no portal E-docente, ainda que estejam participando de processos de avaliação em curso, de obras que se adequam ao objeto 1 do edital: Obras didáticas destinadas aos estudantes, professores e gestores da educação infantil.

Esse sítio na internet é organizado/mantido pelas editoras Ática, Scipione, Saraiva e Atual e utilizado para a divulgação de conteúdos sobre educação, alinhados ao PNLD e à BNCC, e cursos de formação continuada de professores, se apresentando como "a plataforma que contribui para as melhores práticas em sala de aula" (E-docente. Disponível em : https://www.edocente.com.br/ Acesso em agosto/2021)

Nessa plataforma, na seção PNLD 2022, pode-se encontrar a obra "Interação - boas práticas de Educação Infantil" volume 1 e 2 - devidamente identificada com uma tarja informando que se trata de versão para divulgação, que é obra submetida a avaliação e os códigos correspondentes. Trata-se de uma obra voltada para professores e está estruturada em 2 partes: na parte 1 discute fundamentos pedagógicos das propostas para educação infantil, na parte 2 traz Itinerários pedagógicos, orientando as práticas a serem desenvolvidas. Como explicado na introdução:

Este Manual tem como objetivo ajudar o educador a promover o desenvolvimento das crianças nos anos iniciais de vida que estão sob sua responsabilidade. Está organizado da seguinte forma:

- uma parte conceitual - em que apresentamos os fundamentos para o trabalho, as orientações governamentais e a nossa proposta;

- uma parte operacional - em que apresentamos os dois tipos de atividade que fazem parte do dia a dia de uma instituição de Educação Infantil: as rotinas, assim chamadas por seu caráter repetitivo, e as demais atividades com intencionalidade.

Nesta parte apresentamos:

- os instrumentos de trabalho;

- como integrar os instrumentos de trabalho ao dia a dia;

- o detalhamento de algumas orientações.

Essas informações permitirão a você integrar teoria e prática e usar todos esses recursos, de forma consistente com a proposta pedagógica da instituição em que você trabalha. (Batista, 2020, p.5 IN: https://www.edocente.com.br/pnld/2022-infantil. Acesso em setembro/2021)

$\mathrm{Na}$ "parte operacional" a estrutura das unidades traz uma pequena apresentação e, em sequência, as seções: objetivo pedagógico, como fazer e um quadro com os objetivos de desenvolvimento em destaque com seus códigos que evidenciam a relação/adequação à BNCC. Na verdade, observa-se a transmutação do objetivo em indicador, o que é também 
disposto no Anexo I do mesmo edital que apresenta o Glossário do PNLD2022 e nesse, na parte que lista os termos referentes as especificações pedagógicas das obras, consta:

18. Objetivos pedagógicos - são as metas a serem perseguidas por meio da exposição de conteúdos, as quais, para a faixa etária alvo deste edital, dizem respeito às metas preceituadas pela PNA e pela BNCC (Brasil/FNDE, 2020, p.2122)

Tal alinhamento também se observa nas políticas de avaliação. No documento Sistemas de avaliação da Educação Básica - Documentos de Referência (INEP, 2019), apresenta-se o esforço empreendido para alinhar as matrizes de avaliação à BNCC, chamando atenção que a Resolução que a institui define que os sistemas de avaliação devem estar alinhados à BNCC:

Art. 16. Em relação à Educação Básica, as matrizes de referência das avaliações e dos exames, em larga escala, devem ser alinhadas à $\mathrm{BNCC}$, no prazo de 1 (um) ano a partir da sua publicação. (Brasil, 2017, p.11)

Apresenta um estudo sobre os documentos de referência as métricas do processo. No capítulo 6 - Matrizes de referência para os testes cognitivos do SAEB, explicita-se por área do conhecimento esse processo, no detalhamento do que então passa a compor as matrizes e enfatiza-se os termos desse alinhamento, como por exemplo:

A partir das definições dos Eixos da Matriz, foram descritas habilidades do teste para cada cruzamento, tomando como referência as habilidades da BNCC. O exercício consistiu na leitura minuciosa de cada habilidade da BNCC e sua transposição para os cruzamentos originados a partir dos eixos definidos na Matriz. Por exemplo, a habilidade EF07CI10 da BNCC - "Argumentar sobre a importância da vacinação para a saúde pública, com base em informações sobre a maneira como a vacina atua no organismo e o papel histórico da vacinação para a manutenção da saúde individual e coletiva e para a erradicação de doenças" transposta para a Matriz do teste como habilidades passíveis de medição nos três processos cognitivos, conforme mostrado no Quadro 15. (BRASIL/MEC/INEP/DAEB, 2019, p.119-120)

A leitura do cruzamento desses dispositivos normativos nos permite afirmar acerca do investimento no controle e regulação do trabalho docente a partir dessas articulações que vão delineando contornos rígidos às práticas consideradas como boas/melhores práticas. No que incide sobre o trabalho docente, é possível ver como tais processos de gerenciamento do trabalho pedagógico minam a autonomia/autoria dos professores que, ao alinharem suas práticas aos modelos fixos e homogeneizados, acabam vendo estabelecer-se, de forma impositiva, padrões universalizados para práticas de forma descontextualizada. Cabe seguir, aplicar, adaptar para manter-se fiel aquilo que é descrito como fator que qualifica seu trabalho. Dito isso, é possível também observar como drasticamente tal perspectiva também 
atinge a relação estabelecida entre a comunidade e a escola: a confiança, antes depositada no trabalho do professor, nas ações desenvolvidas nas escolas se move e é depositada agora nos resultados. As avaliações, os rankings são vistos como evidências que asseveram a qualidade do processo pedagógico, então o trabalho docente é posto à prova, é preciso passar pelo crivo da avaliação e ser afiançado pelo resultado. No dizer de Biesta (2020, p.21), "a confiança teria sido substituída pelo cálculo".

A responsabilização é uma via de mão única, só voltada para a direção do resultado em caso positivo, o que se destaca não é o trabalho docente, mas a precisão e clareza dos parâmetros traçados, em caso negativo, aí sim o trabalho docente figura como fator decisivo para essa resposta. Os parâmetros, indicadores, objetivos estão a salvo de qualquer responsabilidade na produção desse resultado. Assim, os docentes são destituídos do poder decisório frente aos encaminhamentos do trabalho, cabe-lhes, recorrendo a linguagem utilizada na auditoria de processos, estar "conforme" o que está descrito do processo.

A ideia de cultura de auditoria, segundo Kridel (2010), tem sido usada para se referir a e teorizar a emergência de práticas regulatórias e da linguagem de sistemas de negócios e dos valores que as acompanham, onde a qualidade é atrelada a lógica gerencial, nos processos educacionais. Daí termos como resultados, garantia de qualidade, responsabilidade, transparência, eficiência, melhores práticas circulam e ancoram propostas educacionais.

Taubman (2009) também se refere a essa cultura de auditoria: conceitos e valores de modelos econômicos que passam a regular os processos educacionais impondo controles gerenciais e padronizações tornando auditáveis os processos educacionais; "questões de qualidade estão subordinados às lógicas de gestão e em que a auditoria atende como uma forma de meta-regulação (p.108)", nesse caso, os números passam a significar a qualidade do processo, visto em termos quantificáveis e mensuráveis. Um desejo de controle que se antevê como promessa de sucesso, expresso em resultados. Daí rotas seguras, que possam pavimentar esse caminho de sucesso, são requeridas e defendidas: não há possibilidade de desvios e atalhos; linearidade, sequências, padronizações, roteirização podem atestar o processo; propostas genéricas que mantém a salvo de incertezas o objetivo de qualidade da educação.

Uma das principais características de processos de auditoria é a rastreabilidade. A partir da definição de padrões que estabelecem a qualidade desejada há que se criar mecanismos que permitam verificar e mensurar a qualidade. Para isso, é preciso criar indicadores de controle para que a aferição possa ser feita. No caso, o resultado do indicador retroalimenta o processo, caso seja necessário revisitar as definições estabelecidas. Os indicadores permitem essa rastreabilidade dos itens. Nos termos gerenciais, o que é possível de ser rastreado é aquilo que pode validar o resultado. Nos deslizamentos dessa lógica na educação, o que é rastreável são os códigos que permitem o "inventário" do que é ensinado. Também nesse deslizamento os professores são à submetidos a lógica de accountability, responsáveis pelos produtos gerados e é esse foco no produto/resultado que demanda o controle e regulação dos processos.

Essa ideia de uma cultura de auditoria vem sendo discutida por pesquisadores em diferentes contextos (Apple, 2005; Shore, 2008; Thompson e Cook, 2013; Spooner, 2019) 
que destacam como essa lógica se espraia e vem modelando políticas curriculares. Shore (2008) argumenta acerca de como a cultura de auditoria incide não apenas sobre o trabalho docente, mas tem efeitos em processos de subjetivação que passam pela interpelação de sermos auditados e auditáveis, uma governamentabilidade que extrapola a lógica de accountability e tem efeitos corrosivos no senso de profissionalismo e autonomia docente.

Também Clarke (2013), analisando a compreensão de politcs e policy, o que com Mouffe (2015) ora temos compreendido como a política e o político ${ }^{2}$, analisa, a partir do estudo do caso australiano, como os discursos de formuladores das políticas apresentam as questões em que se como sendo restritamente de ordem técnica, esvaziando a natureza política dessas formulações. Recorrendo ao diálogo com a teoria da hegemonia de Laclau e Mouffe (2001) e trabalho de Glynos e Howarth (2007) (apud Clarke, 2013) acerca de indicativos teóricometodológicos de pesquisas que se referenciam na teoria do discurso, Clarke (2013) discute o papel da fantasia na política como relacionado a impossibilidade de fechamento total. A fantasia, na perspectiva lacaniana referenciada, se move na tentativa de alcançar a plenitude - sempre impossível. Seu papel na política, argumenta o autor, no caso em análise, incide sobre a despolitização em relação ao enquadramento do trabalho docente na revolução educacional (p.304).

Recorrendo a leitura fantasmática acerca da propagação de discursos técnicos, Clarke chama atenção para a dimensão afetiva que permite-nos discutir como esse discurso se propaga e articula:

[...]o estabelecimento e reprodução deste instrumentalismo são amparados por um discurso consensual, que resiste à leitura do espaço educacional em termos de antagonismo social ou político, com a consequência de que o constituía fora do consenso, isto é, o dissenso, torna-se ilegível e impensável. Na base deste consenso instrumental está uma série de fantasias - da salvação do estado-nação harmonioso e exponencialmente próspero através da educação - que vai alguma forma de explicar a "pegada" afetiva do que chamei de contemporâneo duopólio instrumental e consensual. (Clarke, 2013, p.307 - tradução livre) ${ }^{3}$

Sobre isso, Taubamn (2009) também volta a sua atenção, no capítulo em que questiona como a estandardização e a lógica do accountability ecoam e contam com a aderência dos professores, pondo em destaque a fantasia e o imaginário cultural que criam elos que trariam para a profissão uma imagem reconhecida de eficiência e respeitabilidade. Numa análise que articula diferentes dimensões, observando a prevalência de uma cultura de auditoria e como a linguagem da ciência incidiu sobre a percepção dos professores acerca desse discurso, o autor recorre a dimensão afetiva numa perspectiva psicanalítica para observar como a fantasia e o desejo que faz frente ao medo do fracasso, articula e reforça uma agenda proposta pela cultura de auditoria.

Oliveira e Lopes (2021) também tratam dessa temática argumentando acerca da necessidade de discutir o investimento afetivo na política, o que no dizer das autoras, implica em pensar como os investimentos afetivos participa das disputas por significação. 
Nessa linha argumentativa, Safatle (2016) também discute o medo como afeto político. A instauração política implica a capacidade de ser afetado, nesse sentido a política é um modo de produção/circulação de afetos, o que o autor explica a partir das metáforas corpóreas acerca do social:

as metáforas do corpo político nos lembram como não é possível haver política sem alguma forma de incorporação. Não há política sem a encarnação, em alguma região e momentos precisos, da existência da vida social em seu conjunto de relações. Pois é tal encarnação que afeta os sujeitos que com- põem o corpo político, criando e sustentando vínculos. Encarnação que pode se dar sob a figura do líder, da organização política, da classe, da ideia diretiva, dos vínculos a certos arranjos institucionais, da lavadeira; mas que deve se dar de alguma forma. Ignorar esse ponto é um dos maiores erros de várias formas de teoria da democracia. Uma encarnação não é necessariamente uma representação, mas um dispositivo de expressão de afetos. Sendo assim, podemos pensar a política a partir da maneira como afetos determinados produzem modos específicos de encarnação. (Safatle, 2016, p.17-18)

Daí explana acerca do medo e da esperança como afetos políticos e como esses se articulam, inferindo que ambos mobilizam uma temporalidade que tem um horizonte de expectativa - seja num sentido negativo ou positivo, há uma espera e/ou uma promessa a se cumprir que estabiliza o movimento dos sujeitos no interior de um corpo político unitário.

Assim, o autor argumenta, a partir de uma perspectiva freudiana, acerca da produtividade do desamparo como afeto político. Desamparo como desassossego a partir da despossessão e des-identificação; é indeterminado porque quebra com o elo que prende um corpo unitário, que não se acorrenta ao que gera medo, nem fica à espera da promessa a ser cumprida porque essas são sempre imagens de um caminho possível de ser antecipado. O desamparo joga com a contingência e a imprevisibilidade, no dizer do autor, uma outra temporalidade é mobilizada, uma simultaneidade espectral (p.19) que nos permite múltiplos tempos; a contingência é disruptiva, não encontrando lugar na determinação, incitam outras temporalidades e processualidades singulares.

Chama atenção nas argumentações dos autores postos em diálogo aqui a dimensão afetiva reconhecida como partícipe do processo de instituição política. Carvalho (2012) em diálogo Espinoza, destaca o imbricamento entre razão, afetos e afecções na potência da ação. $\mathrm{Na}$ discussão que faz, a autora toma o currículo como comunidade de afetos e afecções defendendo a articulação de dimensões conversacionais e afetivas como potência política, abertura ao devir.

Safatle (2016), no intento de discutir que não há política sem corpo, volta o olhar para o campo biológico para daí discutir a vida política. Em sua reflexão, discute a partir do trabalho de Calliguem, como os fenômenos sociais alinham-se a organização vital. Dessa discussão destaca a questão da normatividade, aqui uma normatividade como potência e atividade que inaugura formas singulares, uma vez que desloca a normatividade como advinda da resposta, em meio a uma experiência relacional, dos indivíduos e não mais uma normatividade do 
meio, que se assenta num registro fixado e que exerce uma força coercitiva. Da afirmação de Calliguem de que a vida é atividade normativa, o autor explicita a potência normativa como forma de responsividade à imprevisibilidade do meio, o que gera novas e outras formas de vida. Para explicitar a potência normativa de vida o autor dá sequência discutindo a distinção entre outras questões, entre o normal e o patológico, o que aqui me interessa pôr em destaque.

Para tanto, trata em termos de normalização e esclarece que esse precisa de um sistema de medidas para se orientar. O normal passa pela definição de padrões mensuráveis que delimita o que é normal, aceito, possível, e o que rompe/excede/falta/desvia da medida vigente. Assim, há um conjunto de regularidades predeterminada a ser conservado e que se marca por uma atividade normativa polarizada. No desenvolvimento da ideia acerca da normalidade/patologia e normatividade o autor afirma que "quando a diversidade orgânica não implica tal polarização, a diferença não aparece como doença (p.518)". Trazer essas ideias ao campo do social nos permite entender uma normatividade fixada reguladora que também delimita, com precisão e clareza, a fronteira do normal/anormal. Ainda que a argumentação de Safatle (2016) vá em direção oposta a uma normatividade impositiva, nas inflexões acerca do trabalho de Calliguem na defesa de uma normatividade transitiva e errante, como acontecimento contingente, o caminho percorrido na problematização interessa na compreensão das redes de afetos e afecções mobilizadas por dispositivos de regulação assentados numa normatividade polarizada.

A ideia de normalização a partir de padrões mensuráveis me permite traçar o elo que liga a normalização à cultura de auditoria, observando uma dimensão afetiva que incide sobre as formas que enredam os professores nesses discursos. O reconhecimento do seu trabalho passa a se dar a partir dos imperativos dos resultados, um reconhecimento de uma visibilidade tamanha que ofusca, se não apaga, outras dimensões, subsumidas numa relação dual, inscrita na polarização que permite a comparação entre o que é certo/errado.

Fragilizado pela ameaça do fracasso e restrito a essa relação dual, o discurso que garante a qualidade se não seduz, protege ou conforma. A despolitização da política impetrada pela ênfase na técnica isenta, voltada para qualificação da ação, interdita a errância apontada por Safatle (2016), emudece a dimensão conversacional defendida por Carvalho (2012), nega a dimensão do afeto sinalizada por Oliveira e Lopes (2021). Os dispositivos de regulação do trabalho docente operam para que esse emudecimento se dê, para a dissociação razão e afeto se mantenha e fortaleça, para conter as contingencialidades, estabelecem certezas que intimidam e aí enfraquecem e colocam como fator a ser superado a dúvida, as singularidades, as interrupções, invenções ou tudo que não se presta a domesticação e padronização que cria a imagem a ser refletida nas práticas pedagógicas. Frente ao espelho só são previstos imagem e reflexo e nada entre eles.

Num contexto em que ordenadamente tudo tem lugar, regido pela precisão e antecipação, faço me acompanhar de Derrida (200, p.258) em busca da modalidade irredutível do talvez, [...] que nos priva de toda segurança e deixa o porvir a porvir". 


\section{Notas finais}

O exercício de análise aqui proposto, ao focalizar o uso dos códigos alfanuméricos, teve por objetivo observar os recursos utilizados na BNCC que participam da construção e colaboram com o fortalecimento de um discurso curricular que se assume como pautado na eficiência, técnica em prol da qualidade do processo educacional. Se num primeiro momento, os códigos podem parecer apenas uma questão organizacional, contudo, mais que isso, os códigos são usados como uma maquinaria para difundir e projetar a qualidade almejada, estabelecendo as regras para um cálculo maquímico que, na problematização feita, incide sobre a regulação do trabalho docente assentada numa normatividade impositiva.

Os códigos dão uma visibilidade exaustiva a BNCC e costuram os nexos entre essa e políticas de avaliação, de formação docente, de material didático, ... É a marca da presença, aqui indicada como originária, unidade total que significa um tempo homogêneo de repetição sucessiva. Busca-se reproduzir um discurso, contendo o efeito de incerteza que uma abertura a outras formas de pensar/fazer currículo poderiam fazer emergir, essas vistas como ameaça.

Medo, ameaça, certeza trazem à tona questão que vem sendo desconsiderada nas análises políticas: a dimensão afetiva. No caso em foco, a dimensão afetiva destacada pelos autores convidados ao diálogo precisa ser considerada em como é mobilizada nessa maquinaria do cálculo, como efeito dos discursos que enfatizam a técnica, a programação ordeira, a precisão e clareza que desenha um horizonte programável e como efeito, o que foge a ordem é vivido, sentido como ameaça a que se deve resistir. Daí que, de forma paradoxal, uma cultura de auditoria se fortalece e se espraia na tensão entre a ameaça/promessa que traz consigo.

Ler o fluxo desses discursos, tal como proposto aqui, visa sondar os cálculos e pensar para além, naquilo que é interditado. Ensinar por códigos pavimenta o caminho programável, antecipável, escrutinado de tal forma que imprevisibilidades não tem espaço; não à toa que o verbo pavimentar parece-me adequado aqui, reforçando a ideia de um caminho construído sem falhas. É exatamente isso que é preciso ser abalado: o determinismo, a obsessão pela certeza (Miller, 2014) e controle de forma tal que o inesperado se torna impossível. E aqui encontro uma perspectiva que tem se tornado cara para mim, nos movimentos de encontro com Derrida, e que tem me afetado: o incalculável, o indeterminável, o outro, a diferença, não como resto ou algo que preciso achar um lugar e "pôr na estante no meio da bugiganga", reduzindo o outro ao mesmo, tampouco trata-se de submetê-lo a condição de anômalo. Impossível como condição de possibilidade. Imprevisível, indecidível, o outro que chega como acontecimento que excede o cálculo, transborda. É preciso rasurar os códigos, naquilo que ele tenta obliterar. A precisão e clareza que eles insinuam garantir são estratégias de fechamento, investimento numa unidade da totalidade.

É essa unidade que precisa ser combatida, problematizada em favor da abertura, da ruptura, da singularidade. E não se trata de um combate numa lógica substitutiva, na busca do que se põe nesse lugar. É a abertura que não teme o que chega de forma imprevista. É essa chegada que possibilita pensar em porvir. 


\section{Notas:}

1. No original: What we are witnessing today is something new, and something much more dangerous than a worship of science or the "cult of efficiency." Its uniqueness lies in its pervasiveness, its threat to the very foundations of public education, its wide embrace by the educational establishment, its direct assault on the intellectual, aesthetic, and ethical life of teachers, and its radical misunderstanding of teaching.(Taubaman, 2009, p.5)..

2. "[...] a política se refere ao nível "ôntico, enquanto "o político" tem a ver com o nível ontológico" Isso significa que o ôntico tem a ver com as diferentes práticas da política convencional, enquanto o ontológico refere-se precisamente à forma em que a sociedade é fundada" (Mouffe, 2015, p.8).

3. 3. No original: "the establishment and reproduction of this instrumentalism are supported by a consensual discourse, which resists reading the educational space in terms of social or political antagonism, with the consequence that the constitutive outside of consensus, that is, dissensus, is rendered unreadable and unthinkable. Underpinning this instrumental consensus are a number of fantasies - of the salvation of the harmonious and exponentially prosperous nation state through education - which go some way to account for the affective 'grip' of what I have referred to as the contemporary instrumental and consensual duopoly (p.307).

\section{Referências}

APPLE, Michael. Education, markets and audit culture. Critical Quaterly, v 47, ju/2005, p.11-29.

BATISTA, J. Interação - boas práticas de educação infantil. Volume 2. São Paulo: Editora Ática, 2020. Disponível em: https://www.edocente.com.br/pnld/2022-infantil. Acesso em setembro/2021

BHABHA, H. O local de cultura. Belo Horizonte: UFMG, 2001

Nuevas minorías, nuevos derechos - notas sobre cosmopolitismos vernáculos. Buenos Aires: Siglo Veintiuno Editores, 2013.

BIESTA, Gert. Para além da aprendizagem: educação democrática para um futuro humano. Belo Horizonte: Autêntica Editora, 2020.

2012.

Boa educação na era da mensuração. Cadernos de Pesquisa, v42, n147, p.808-825. Set/dez,

BRASIL. Resolução CNE/CP no 2, de 22 de dezembro de 2017 - Institui e orienta a implantação da Base Nacional Comum Curricular, a ser respeitada obrigatoriamente ao longo das etapas e respectivas modalidades no âmbito da Educação Básica.

BRASIL. Ministério da Educação. Base Nacional Comum Curricular. Brasília: MEC, 2018. Disponível em: http://basenacionalcomum.mec.gov.br/a-base.

BRASIL/MEC/INEP/DAEB. Sistema de Avaliação da Educação Básica - Documentos de referência. Versão Preliminar. Brasília, 2019.

BRASIL/FNDE. Edital De Convocação No 02/2020 - CGPLI . Edital de Convocação para o Processo de Inscrição e Avaliação de Obras Didáticas, Literárias e Pedagógicas para o Programa Nacional do Livro e do Material Didático -PNLD 2022.Brasília, 2020.

BUTLER, Judith et al. Debates feministas - um intercâmbio Filosófico. São Paulo: Editora UNESP digital, 2018.

CARVALHO, Janete Magalhães. O Currículo Como Comunidade De Afetos/Afecções. Revista Teias. V.13, 
n 27, 2012.

DERRIDA, Jacques. Papel-máquina. São Paulo: Estação Liberdade, 2004. Gramatologia. São Paulo: Perspectiva, 2011 ${ }^{\mathrm{a}}$ A escritura e a diferença. São Paulo: Perspectiva, 2011b

FRANGELLA, Rita de Cássia. Muitos como Um?: políticas curriculares, justiça social, equidade, democracia e as (im)possibilidades de diferir. Educar Em Revista, v 36 e75647, 2020.

MILLER, Janet. Teorização do currículo como antídoto contra/na cultura da testagem. E-curriculum, v.12, no. 3, p-2043-2063, out-dez/2014.

KRIDEL, C. Audit culture. In: Encyclopedia of curriculum studies (Vol. 1, pp. 60-61). SAGE Publications, Inc., https://www.doi.org/10.4135/9781412958806.n31, 2010.

LOPES, Alice e MACEDO, Elizabeth. Teorias de Currículo. São Paulo: Cortez Editora, 2011.

MOUFFE, Chantal. Sobre o político. São Paulo: Editora WMF Martins Fontes, 2015.

OLIVEIRA, V. B. de; LOPES, A. C. Por que o afeto é importante para a política? Implicações teóricoestratégicas. Práxis Educacional, [S. 1.], v. 17, n. 48, p. 1-22, 2021. DOI: 10.22481/praxisedu.v17i48.8939. Disponível em: https://periodicos2.uesb.br/index.php/praxis/article/view/8939.

SAFATlE, Vladimir. O Circuito dos Afetos: Corpos Políticos, Desamparo e o Fim do Indivíduo. Belo Horizonte: Autêntica, 2 ${ }^{\mathrm{a}}$. Ed, 2016.

SHORE, Cris. Audit culture and Illiberal governance: Universities and the politics of accountability. Anthropological Theory 2008; 8; p. 278-298

SONU, Debbie. Breathing Spaces in Neoliberal Places. An essay Review of Peter Taubaman's Teaching by numbers. Journal of Curriculum Theorizing. Volume 27, Number 3, 2011

SPOONER, M. Technologies of Governance in Context: Four Global Windows Into Neoliberalism and Audit Culture in Higher Education. Qualitative Inquiry, 26(7), 2019.

STRATHERN, Marilyn. Audit Cultures. Anthropological studies in accountability, ethics and academy. London/New York. Routledge, 2000.

TAUBMAN, Peter. Teaching by numbers - desconstruction the discourse of standards and accountability in Education. New York: Routledge, 2009.

THOMPSON, G. and COOK, I. The logics of good teaching in an audit culture: A Deleuzian analysis. Educational Philosophy and Theory, 45 (3), 2013, p. 243-258.

\section{Correspondência}

Autor (nome completo): Rita de Cássia Prazeres Frangella: Professora Associada da Faculdade de Educação da Universidade do Estado do Rio de Janeiro. Professora do Programa de Pós-Graduação em educação - PROPED/UERJ. Procientista/UERJ; Cientista do Nosso Estado/FAPERJ; Bolsista de Produtividade em Pesquisa - CNPq. Foi presidente da Associação Brasileira de Currículo - ABdC no biênio 20192021. Coordena o GRPESq Currículo, formação e educação em direitos humanos - GCEDH. Desenvolve pesquisas sobre políticas curriculares para infância, alfabetização e anos iniciais, formação de professores; currículo, cultura e diferença.

E-mail: rcfrangella@gmail.com 
Texto publicado em Currículo sem Fronteiras com autorização dos autores. 